\title{
Primary plant succession on freshly degraded yedoma (ice complex) in Lena delta (Eastern Siberia)
}

\author{
Nikolay Laschinskiy ${ }^{1,2 *}$, Alexey Faguet $^{2}$, and Christina Biasi $^{3}$ \\ ${ }^{1}$ Central Siberian Botanical Garden SB RAS, Novosibirsk, Zolotodolinskaya str. 101, Russia \\ ${ }^{2}$ Trofimuk Institute for Petroleum Geology and Geophysics, SB RAS, Novosibirsk, Koptug ave. 3 , \\ Russia \\ ${ }^{3}$ University of Eastern Finland, Yliopistokatu 2, FI-80100 Joensuu, Finland
}

\begin{abstract}
Primary plant succession was studied on freshly eroded yedoma in the southern part of Lena River Delta. Four stages of vegetation development were clearly distinguished. The first stage starts on bare ground and lasts from two-three months to one year. Its vegetation is represented only by fragmented cover of young mosses and a few seedlings of vascular plants. The most abundant moss species at this moment is Ceratodon purpureus. The second stage lasts from one to three years depending on slope steepness. Plants cover 20 to $60 \%$ of the soil surface. Main dominants are Descurainia sophioides and Tephroseris palustris. The third stage of succession presented by closed species-poor grasslands with Arctagrostis arundinacea as main dominant. This stage lasts for up to 20 years. The fourth stage is represented by species-rich herbaceous communities, which also have Arctagrostis arundinacea as main dominant but enriched with many perennial herbs. There is not enough data to determine the duration of this stage but it is at least few tens of years. This successional system requires a long time for its development. It means that IC degradation is not a recent process but accompanied yedoma deposits through all of its history.
\end{abstract}

Yedoma or Ice Complex (IC) is a special type of Pleistocene deposits which consists of loam or sandy loam with high organic matter content and 50 to $90 \%$ of ice. Ice is presented in a form of syngenetic wedges about few meters wide and few tens of meters deep [1-3]. It is widespread in extra continental parts of Northern Asia (Yakutia, Chukotka) which were never glaciated [4]. Nowadays IC actively degrades because of climate changes [5]. This degradation is especially active on riverbanks and on lake shorelines. In course of IC degradation ice wedges melt and microbes actively consume soil organic matter. As a result, a lot of nutrition available to plants appears in soil. On slopes this degradation is accompanied by active erosion when wet melted soil slides down slope and partly washes out into the river or lake. This freshly eroded substrate is quickly colonized by plants. Research of this succession is important because plants can slow down the erosion and

\footnotetext{
* Corresponding author: nn1630090@gmail.com
} 
fixate mobile minerals in their bodies. In addition, newly appeared plant communities could be good indicators of certain soil processes.

Study area is located in the southern part of Lena River Delta on islands Kurungnakh-

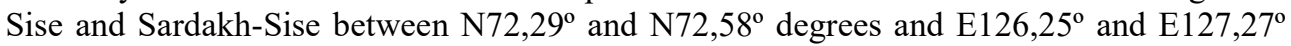
degrees. Both islands belong to the third river terrace [6] and are elevated $40-45 \mathrm{~m}$ above sea level. On both islands there are few big yedoma outcrops overlooking the river banks. Each outcrop is at least $20 \mathrm{~m}$ height and about $100 \mathrm{~m}$ or more long.

In course of vegetation seasons 2017 - 2019 we conducted a field survey to describe the vegetation. We picked and described sample plots $10 \times 10 \mathrm{~m}$ size located in different plant communities (determined visually) on each outcrop. In total we made 87 geobotanical relevés. For each relevé we determined its geographical position with a 12-channel GPS; described its habitat characteristics including position on the slope, microrelief, moisture, etc. and composed a list of species with their projective coverage. Some specimens of vascular plants were collected and identified later in a lab. In the field we also listed some moss species but only ones that are easily recognizable. Later all relevés were placed in the specialized database IBIS 7.2 [7] and classified by their species composition. In the process of classification four stages of vegetation development were clearly distinguished. These stages differ by the structure of their community and composition of species. They replace each other in the course of primary succession on degraded IC.

Vegetation of the first stage is represented by mosses and vascular plant seedlings (Fig. $1, a)$. It starts on bare ground and lasts from two-three months to one year depending on date of starting point. At this stage vegetation is presented only by fragmented cover of young mosses and a few seedlings of vascular plants. The most abundant moss species at this moment is Ceratodon purpureus. Plant identification is quite difficult at this stage because plants are young and not fully developed. This stage may take longer in case of active repeated erosion. Sometimes it includes fragments of tundra vegetation that slides down slope and gradually dies.

The second stage lasts from one to three years depending on slope steepness. Plants cover 20 to $60 \%$ of the soil surface (Fig. 1, b). Species composition is represented by erosiophytes - mostly annuals which usually occur in ruderal habitats in and around settlements south from studied area. All these species are completely absent in surrounding intact tundra and occur only on degraded IC. Main dominants are Descurainia sophioides and Tephroseris palustris. Another characteristic species of this stage is Cochlearia arctica. More and more perennials appear at the end of this stage. Among them - Puccinellia neglecta - a specific plant for this stage and this habitat type.

The third stage of succession presented by closed species-poor grasslands with Arctagrostis arundinacea as main dominant (Fig. 1,c). Vegetation completely covers soil surface. Most of plants are perennials but also occur only in these habitats and do not appear in tundra. Typical tundra plants, shrublets and mosses are rare or absent. Plant communities of this stage produce significant amount of biomass every year and are important forage source for native mammals. Another characteristic feature of this stage is dense litter on soil surface composed of grass remnants. Main dominant species Arctagrostis arundinacea - hits the northern limit of its distribution here. This species is common for the southern tundra and forest-tundra where it occurs in zonal vegetation. This stage lasts for up to 20 years. 


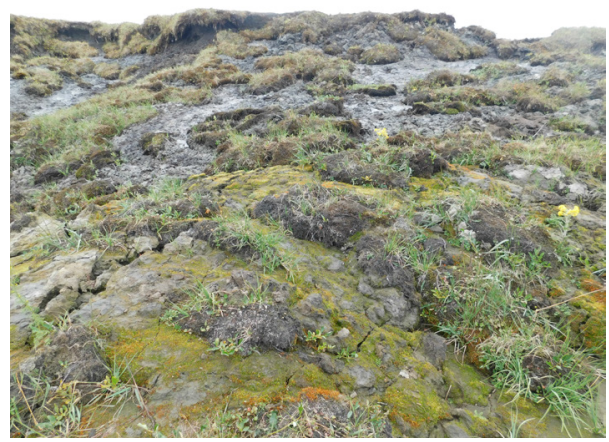

$a$

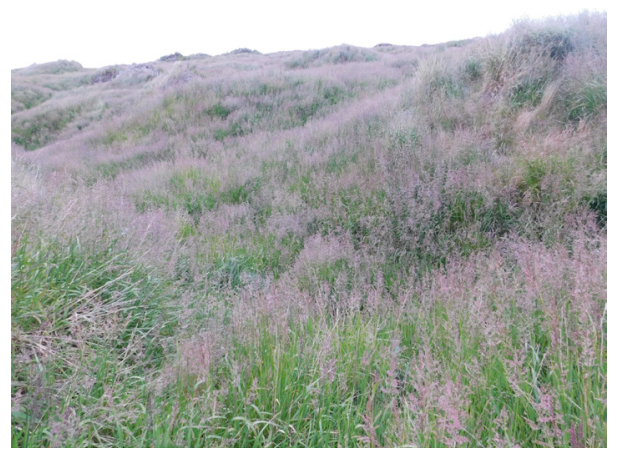

$c$

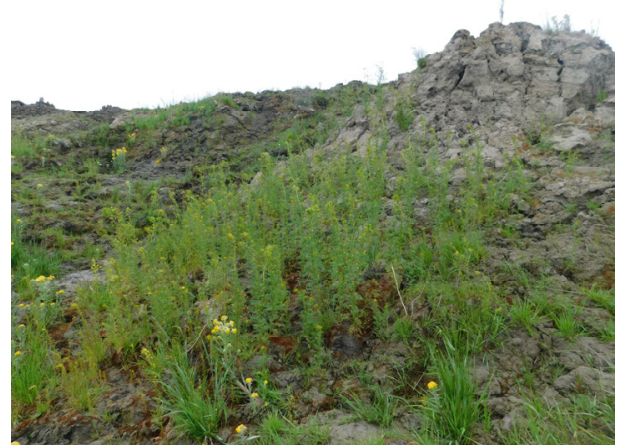

$b$

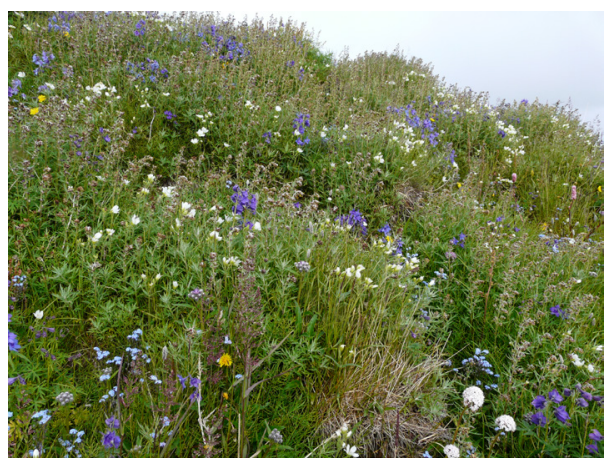

$d$

Fig. 1 Primary vegetation succession on degraded IC. ( $a, b, c, d$ - stages of the succession).

The fourth stage is represented by species-rich herbaceous communities, which also have Arctagrostis arundinacea as main dominant but enriched with many perennial herbs (Artemisia tilesii, Delphinium chamissonis, Saussurea tilesii etc.) (Fig. 1, d). At this stage typical tundra plants appeared in species composition but moss layer is still absent or very weakly developed. There is not enough data to determine the duration of this stage but it is at least few tens of years.

The final succession stage will obviously be characterized by any type of typical tundra plant communities but from our data we are only able to describe the first hundred years of succession. At the end of succession, the main processes will be gradual replacement of pioneer species by tundra species and development of the continuous moss cover on the soil surface.

According to our research there is a well-developed successional system which depends on IC degradation. This system consists of few stages with characteristic plant communities and species for each stage. Such system requires a long time for its development. It means that IC degradation is not a recent process but accompanied yedoma deposits through all of its history. Suitable habitats appeared from time to time along riverbanks and lake shorelines and supported specific plant species and communities in different climate situations during previous epoch.

This study was carried out as part of State Task of the Central Siberian Botanical Garden, Siberian Branch, Russian Academy of Sciences, no. AAAA-A17-117012610052-2, with partial financial support from Russian Foundation for Basic Research grant no. 18-55-11003 AF_t "Assessing the Circumpolar Balance of N2O." 


\section{References}

1. G. F. Lungersgauzen, Geological History of the middle Lena and Some Questions of Quaternary Deposits Stratigraphy in East Siberia in Proceedings of the All-Union Conference on the Study of the Quaternary period, vol. 3. SAS Publishers, Moscow (1961)

2. G. Schwamborn, A. A. Andreev, V. Rachold, H.-W. Hubberten, M. N. Grigoriev, V. Tumskoy, E. Yu. Pavlova, M. V. Dorozhkina, Quaternary International 89, (2002)

3. L. Schirrmeister, V. Kunitsky, G. Grosse, S. Wetterich, H. Meyer, G. Schwamborn, O. Babiy, A. Dereviagin, C. Siegert, Quaternary International, 241 (2011)

4. Tomirdiaro S.V., East Siberian loess-ice formation in late Pleistocene and Holocene. (Nauka, Moscow, 1980)

5. G. Grosse, L. Schirrmeister, C. Siegert, V. Kunitsky, E. A. Slagoda, A. A. Andreev, A. Y. Dereviagyn, Geomorphology 86 (2007)

6. M. N. Grigoriev, Criomorphogenesis in the Lena Delta (Permafrost Institute Press, Yakutsk, 1993)

7. A. A. Zverev Information technologies in vegetation cover investigations (TSU, Tomsk, 2007) 